\title{
Literature Review of Knowledge Sharing and Issues Raised for Vietnamese Universities
}

\author{
Van Sang Do, Thanh Do Nguyen, Manh Dung Tran, Van Nam Le, Quang Minh Doan \\ National Economics University, Vietnam
}

\begin{abstract}
This study aims to review previous studies in the field of knowledge sharing. Data being used in this study was collected from researches related to the topic of knowledge sharing. We summarize literature on knowledge sharing in terms of (i) Necessity of knowledge sharing, (ii) Supporting from information and communication technology tools (ICT), (iii) Context of knowledge sharing, (iv) Participants knowledge sharing, (v) Receiver knowledge and (vi) advantages and disadvantages when participating in knowledge sharing. Some implications are recommended for Vietnamese universities to better support knowledge sharing activities in Vietnam and around the world.
\end{abstract}

Keywords: Knowledge management, Knowledge sharing, Information technology, Management information system.

DOI: $10.7176 / \mathrm{JESD} / 10-18-17$

Publication date:September $30^{\text {th }} 2019$

\section{Introduction}

Over the past two decades, the industrial revolution and fierce business competition have a significant influence on resources, capabilities, strategies, missions and visions of dynamic organizations. Knowledge capital is considered among the most important resources which create competitive advantage and improve survival rate of organizations in a fiercely competitive business environment. An organization may have abundant financial resources, fixed assets, the latest technology, and loyal customers, but human capital is its core competency (Muqadas et al., 2016). Employees engage in the acquisition, creation, sharing and exploitation of knowledge with the wide interest of their organizations (Henri, 2016). According to knowledge theory, knowledge is considered as an intellectual property, a main source of energy and a competitive advantage of the organization (Grant, 1996).

Knowledge development, knowledge lifecycle, knowledge sharing and knowledge gathering are requirements to improve the level of innovation and performance of organizations (Rutten et al., 2016). An organization can make changes such as advanced technology, new products and services, innovation, a supportive culture and a good work environment by focusing on knowledge sharing and learning (Bontis et al., 2009; Goh and Richards, 1997; Imran et al., 2016). However, Connelly et al. (2012) argue that efforts to cultivate knowledge sharing do not guarantee success. Several studies explain the benefits of knowledge sharing, such as how to improve performance and create ideas among employees (Muqadas et al., 2016; Anantatmula, 2007; Henri, 2016); Bringing innovation (Bontis et al., 2009; Svetlik et al., 2007; Muqadas et al., 2016) and changes to an effective organization (Park \& Kim, 2015); Enhancing individual, group and group activities (Haas \& Hansen, 2007); Promote new technologies for success (Lee, 2001). Despite efforts to cultivate knowledge sharing through social media; Creating a culture of knowledge management (knowledge sharing), building trust, intent and involvement among employees, but achieving these goals is still elusive and difficult to implement ( Al Saifi et al., 2016; Bautista \& Bayang, 2015). Moreover, some studies show that even the increased rewards for knowledge sharing and the high level of trust among employees cannot foster knowledge sharing activities (Bock et al., 2005; Chow \& Chan, 2008; Smith et al., 2006; Swap et al., 2001).

Organizations that begin to focus on cultivating knowledge sharing often operate more effectively than those with knowledge hoarding issues (Andolsek, 2011; Hansen, 2002; Muqadas et al., 2016). Organizations have spent numerous amount of money on recruiting, improving, training and staff development (Smith et al., 2006; Muqadas et al., 2016). However, employees often quit their jobs whenever they find a more attractive opportunity, therefore wasting the resources and time their employers invest in them. In public universities, employees tend to accumulate knowledge for personal gain, promotion, authority, authority, influence and the opportunity to excel at work. Knowledge accumulation refers to the maintenance of knowledge with the aim of gaining benefits in the form of power and influence (Andolsek, 2011; Holten et al., 2015; Muqadas et al., 2016).

Many employees in the public sector believe that knowledge sharing can reduce their authority, respect, influence and recognition, which can negatively affect their career and their success in general. On the other hand, Chaudhry (2005) has argued that knowledge is considered an energy source. Therefore, owning it can also become a barrier to share it with others. The lack of a research culture in these public universities is an obstacle to knowledge sharing (i.e. lack of international conferences, very little effort to organize research seminars and webinars on research, few conferences on research software training and no suitable instruction in research 
methods). Moreover, employees have little access to external and internal networks for knowledge exchange and often do not use social media tools for knowledge sharing. Knowledge sharing activities require a supportive culture and employee awareness to share their knowledge, which is not available in public universities. As a result, employees' tacit knowledge is not transferable in case they die, move to another workplace or retire from their organization.

Most studies focus on the private sector or developed countries with high technology firms, supporting cultures and good knowledge sharing activities (Bate \& Robert, 2002; Bontis et al., 2009; Hall \& Mairesse, 2006; Kim \& Lee, 2006; Michael, 2007). Researchers believe it is important to investigate the reasons behind the accumulation of knowledge accumulating among employees in developing countries, especially among public sector scientists (Muhenda \& Lwanga, 2014). Therefore, officials, senior managers and policymakers are working hard to discover the cause of employees' knowledge accumulation in developing countries. In addition, research on public organization's knowledge sharing activities in developing countries such as Vietnam should be strengthened, especially at institutions and universities, where knowledge is researched, created, exploited and applied practically.

\section{Theoretical framework of knowledge and its sharing}

\subsection{Knowledge}

Knowledge is getting more and more important to the sustainable development of businesses, as well as the nation. Research of Grant (1996) has shown that knowledge is one of the factors that make business success and knowledge management has become an effective and most important competitive strategy, while the research of Nelson \& Winter (1982) have proved that knowledge is a decisive factor for the performance of businesses. According to Stiglitz (former chief economist of the World Bank), knowledge plays an important role in economic development and social welfare. The effective usage of knowledge in an organization depends significantly on its people (Stiglitz, J.E. \& Greenwald, 2003). Therefore, individual knowledge as an asset needs to be effectively managed to achieve better performance (Andrews \& Delahaye, 2000; Bartol \& Srivastava, 2002; Refaiy \& Labib, 2009) then in turn achieve sustainable competitive advantage (Cabrera, 2005; Nonaka \& Takeuchi, 1995). However, many organizations still find it difficult to use their knowledge resources effectively to grow their businesses. Are they missing a theoretical framework to help understand the operations of businesses in the knowledge economy?

The question of knowledge nature is a great challenge for scientist. Although philosophers have been discussing this issue for many years, the search for an official definition is still ongoing. From the view point of different researchers, knowledge is defined differently. For example, Nonaka \& Takeuchi (1995) point out that "knowledge is a dynamic process of people in proving personal beliefs with "truth". The evolution of scientific epistemology has formed a hierarchical structure of knowledge creation. Knowledge is a collection of structured connection patterns (Meyer \& Ugiyama, 2007). Knowledge is also defined as (i) event, information and skills acquired by a person through experience or education, theoretical understanding or practice of a problem, (ii) what is known in a particular or whole area; facts and information; or (iii) raising awareness or understanding gained by experience of an event or situation (Amrit Tiwana, 1999). Knowledge can be defined as "information associated with experience, context, interpretation and reflection". Knowledge is a resource to create value in a firm (Mohanty, 2003).

According to Nonaka (1995), there are two types of knowledge. Firstly, explicit knowledge can easily be transferred and created, for example, a manual, a book or a knowledge store written in any form. Second, tacit knowledge is the type of knowledge stored in a person's head and is "without words, visual and without communication" (Polyani, 1962). Therefore, this type of knowledge can be difficult to transfer and according to Reychav and Weisberg (2010) it is considered more valuable.

Lowendahl et al. (2001) identify three types of knowledge that individuals share, namely know-how, innate knowledge, and knowledge. Accordingly, knowledge is based on subjective experience, knowledge related to objective tasks, and innate knowledge related to individual talents, talents and abilities.

In short, researchers in the world have many approaches and perceptions of knowledge which possess some similarities and also some differences. Future research needs to verify these perceptions of knowledge through empirical research, implemented in different contexts, spaces, times, and firms, especially in institutions such as universities and institutes with training and research.

\subsection{Knowledge sharing}

Knowledge sharing is an important aspect of knowledge management, possibly also of the organization's sustainable competitive advantage. Through knowledge sharing, an organization can integrate both internal and external knowledge to detect opportunities and gain more favorable conditions during its operations (Gavirneni et al., 1999). Although knowledge sharing results improve the organization's performance, few businesses have successfully encouraged and enabled employees to share their knowledge to support activities, regarding the 
organization. Some difficulties and barriers might be encountered such as lack of resources and technology training, differences in personal skills, no time to participate in knowledge sharing (Riege, 2005). Moreover, another factor determining the success or failure of knowledge sharing is the motivation of individuals to participate in creative activities and share knowledge in the community (Jolaee et al., 2014).

Knowledge sharing is an important part of organizing knowledge management within an organization (Hoq \& Akter, 2012; Nove \& Dyah, 2013; Sohail \& Daud, 2009). Knowledge sharing is a key part of knowledge management (Fengjie et al., 2004). Knowledge sharing asserts that knowledge is accessible and distributed (Carmen et al., 2011; Hussein \& Nassuora, 2011). The most ideal approach to bringing together a healthy society in knowledge management is through knowledge sharing (Nassuora, 2010). Knowledge sharing is a voluntary human behavior that helps members of an organization share and use new knowledge with each other (Nonaka, 1994). Knowledge sharing activities encourage employee creativity and organizational performance (Muqadas et al., 2016; Inkinen, 2016).

Knowledge sharing and organizational knowledge are based on social exchange and social capital. SETSocial exchange theory explains that individuals share their knowledge because of their perceptions of possible benefits of that behavior. In essence, individuals within a community or organization are provided with an environment to support positive awareness and are more likely to contribute their knowledge to the organization (Liang et al., 2008). SET also explained that individuals adjust their interactions with others based on an analysis of the costs and benefits of that interaction. In other words, people seek to maximize their benefits and minimize their costs when exchanging resources with others (Molm, 2001). These benefits include future, job security, balance of power and maintenance of future relationships (Bock et al., 2005; Cabrera \& Cabrera, 2005; Muthusamy et al., 2007). It can help explain the dynamics of individual behavior in a community or organization to knowledge sharing (Zboralski, 2009) because knowledge sharing requires the willingness to collaborate with others. From this perspective, knowledge sharing is positively affected when an individual hopes to gain some future benefits through reciprocity (Cabrera et al., 2006). SET has been used in a number of studies in developed countries as a theoretical model to investigate individual knowledge sharing (Blau, 1964; Casimir et al., 2012; Eunjee, 2009; Kankanhalli et al., 2005; Liang et al., 2008). Kankanhalli et al. (2005) explain that an individual's benefits and perceptions are one of the main factors that encourage employees to contribute knowledge to the electronic knowledge archive. Chiu et al. (2006) also investigated the effects of interpersonal factors such as social interaction, trust and reciprocal norms on knowledge sharing in virtual communities.

The "social capital" theory explains that knowledge sharing occurs because it benefits social benefits (such as enhanced reputation) for both sharers and firms (Nahapiet and Ghoshal, 1998). Social capital acts as a system of standards and therefore can be a source of social control to encourage people to refrain from unwanted behaviors, such as social fear, which is a General risk in knowledge sharing (Lang, 2004). However, if knowledge is considered as an individual property through which an individual has complete control, the decision to share knowledge is based on an assessment of the individual's costs and benefits. That (Cabrera and Cabrera, 2005).

\section{Literature review of knowledge sharing}

Through literature review of the research results, the research team can draw out some of the following key knowledge sharing issues:

\subsection{The necessary to knowledge sharing}

David Gurteen (1999) states that the creation and application of knowledge today is essential for the existence of most businesses. There are many reasons for this argument, such as (i) Intangible products such as ideas, processes and information account for a growing proportion of global trade instead of traditional goods and tangible assets of the manufacturing economy; (ii) Increasing sustainable competitiveness and continuous innovation; and (iii) When someone leaves an organization, their knowledge leaves the organization. The question is how to maintain and store that knowledge, to keep that knowledge from disappearing from the organization?

Knowledge sharing is necessary for an organization to succeed, because it can facilitate decision making, build learning organizations (through study habits) and, ultimately, stimulate cultural change and innovation. However, the overall performance in an organization only improves when working people make a difference (Murray, 2002). Postolache (2017) states that the right knowledge sharing will (i) Make the best problem solving organization reusable. Knowledge sharing also helps improve communication between employees, both internally and across organizations. Members of an organization can significantly improve their relationships by sharing and managing knowledge properly, regardless of whether they work in the same department or differently. (ii) Enables better and faster decision making. When customers are having problems or you have to solve internal problems such as: trend analysis, understanding competition or planning new strategies. However, using knowledge multiple times in the repository allows you to make decisions based on the practical experience of the members of your organization. All of this can be done effectively if it is easy to find what you need and most importantly when you need it, it is there. (iii) Stimulate innovation and growth. (iv) Improve delivery for customers. Customers appreciate 
a firm that can demonstrate extensive expertise and the ability to use it in their interests. In addition, the ability to deliver on time is essential and can help a firm differentiate itself from competitors. Knowledge sharing and innovation can certainly reduce the time it takes to deliver a product or service, leading to increased win rates and, of course, increased customer satisfaction. (v) Reduce the loss of know-how. Know-how is an important asset in every firm and it needs to be properly exploited and managed. Through knowledge sharing, firms can capture tacit and implicit knowledge and ultimately reduce losses.

\subsection{The support of information and communication technology tools}

Several information and communication tools (ICTs) can be used to support and enhance knowledge sharing and enable effective knowledge transfer (Alavi \& Leidner, 2001; Becerra Fernandez et al., 2004; Davenport \& Prusak, 1998). ICTs can support informal knowledge sharing through network technologies such as email, messaging, chat rooms, discussion forums, newsletters, videoconferencing and online conferences or Official sharing support through information repositories, document management systems, databases / data warehouses, collaborative author systems, work systems and coordination systems and / and portal business news. Moreover, ICTs can also be used to enable knowledge transfer through the creation of specialist directories; search profiles of knowledge experts (Alavi \& Leidner, 2001; Davenport \& Prusak, 1998). With the advent of Web 2.0 technology, Huck et al. (2011) proposed the use of wikis, blogs, social networking sites and open source software, Fliker and YouTube as knowledge management solutions.

Some of the technologies commonly used to support information systems that cross the boundaries of a specific organization include electronic data exchange and extended networking (Rainer et al., 2007). According to Chi \& Holsapple (2005), technologies such as the internet, wireless networks, peer-to-peer and wireless communications can be used to develop inter-organizational systems. Electronic centers Web services, widespread application of common enterprise resource planning systems and enterprise gateways can also be used to support inter-organization systems integration (Daniel \& White, 2005).

At the same time, the diverse combination of teams and the limited face-to-face communication between firm members make the process of knowledge sharing more complicated. Gibson \& Gibbs (2006) have shown that the "virtual" characteristics of teams can be dangerous to creativity. According to Brown and Eisenhardt (1995), the diversity of nationality and electronic dependence has a negative impact on creativity and knowledge sharing. Besides, because firms cannot have long-term human capital, many firms choose to use information technology to: (i) Facilitate knowledge sharing; (ii) Maintaining knowledge within an organization and (iii) Facilitating knowledge development from individual to organizational level (Yi et al, 2008). According to Muqadas et al. (2017), the lack of a research culture in public universities is an obstacle to knowledge sharing (i.e. lack of international conferences, with very little effort to organize webinars and seminars). In terms of research, there are few conferences on research software training and no appropriate instruction in research methods. Moreover, employees have less access to external and internal networks to exchange knowledge and often do not use social media tools for knowledge sharing. Factors such as employee retirement, death or job transfer negatively affect knowledge sharing activities.

\subsection{The context of knowledge sharing}

The process of combining and exchanging knowledge is based on social relationships. Nahapiet \& Goshal (1998) argue that this process is strongly supported by social capital. Social capital can be considered as a network of relationships, creating a valuable resource for the exchange of knowledge. Von Krogh (1998) also implicitly recognizes that people in a highly caring environment, where they trust each other and are willing to help their colleagues, all strive to achieve "the highest leverage effect on knowledge of others". The value of individual knowledge is seen as important and effective for the collective. In an environment of little attention, people are directed to their own efficiency and strive to achieve the "highest level of understanding" in their context, regardless of the problems of other colleagues. Knowledge sharing in an environment of low interest takes place in the form of transfers in which "paid" funds are expected. In addition, in an environment of little interest, the sharing of tacit knowledge depends on the social constraints related to the work of the participants. Michailova \& Hutchings (2006) show that Chinese and Russian's firms exchange knowledge in a harmonious and bargaining manner. In an environment of little attention, knowledge sharing is a desirable action in which there is a difference between information-sharing and information-gathering people (Ardichvili \& Wentling, 2003). Schulz (2001) also distinguishes the flow of knowledge in and out. This study focused on the flow of knowledge in and between units and firms in relation to the uniqueness of knowledge. Research has shown that the knowledge associated with strategy and marketing moves faster than technical knowledge.

The difference between giving and receiving information is clear in an educational or other setting where people must be instructed or informed. It becomes less obvious in the case of ongoing knowledge exchange, such as in groups performing joint tasks. Unlike knowledge transfer by notification or instruction, knowledge sharing is considered in this research context as a highly communicative process, in which the roles of contributors and 
reception is continuously converted. Osterloh \& Frey (2000) as well as Krogh (1998) point out the importance of participation and personal relationships for knowledge sharing among teams.

The literature provides evidence that there is a difference in the use of knowledge-sharing mechanisms. For example, in a comparative study conducted in Hong Kong and the construction industry in the United Kingdom, Fong \& Chu (2006) provided evidence that in the Hong Kong construction industry The institution is used to share knowledge mainly including meetings, phone calls, telephone conferences, intimate conversations and storytelling. And discussion groups, web-based discussions, knowledge sharing guides, and the Internet are rarely used. Fong \& Chu (2006) provided evidence that the construction industry in England mainly used intimate talking, storytelling techniques, followed by telephone calls and teleconferencing. And meetings where knowledge sharing boards, newsgroups and web discussions has never been used. Jones and Borgman (2007) find that the widely used mechanisms by leading executives of several industries in the US are e-mail and knowledge repositories, while discussion forums seldom used. Moreover, in the context of public and private sector in Bahrain, Al-Alawi et al. (2007) have found collaboration and teamwork as widely used mechanisms for knowledge sharing.

\subsection{Knowledge sharing people}

David Gurteen (1999) states that knowledge is understood as a perishable type and it is increasingly short-lived. If you do not use your knowledge then it quickly loses its value. By sharing your knowledge, you will gain more than you lose. Knowledge sharing is a synergistic process, you get more of what you offer. If I share an idea, product, or way of working with others, just taking my idea in writing will help me conceive and improve it. If I talk to others, I will benefit from their knowledge, from their unique insights and improve my ideas. Today, for an organization to be even more successful, cooperation efforts are required. If you try to work alone, you may fail. If you are open, sharing and cooperating with them, they will help you achieve your goals". When employees are willing to share their knowledge, an overlapping amount of knowledge and mission-related knowledge is needed. The mismatch of interpretation and the lack of similar knowledge create cognitive gaps among group members. This gap needs to be leveled by the learning and coordination processes of specialist knowledge (Faraj \& Sproull, 2000; Bogenrier \& Nooteboom, 2004). Wasko and Faraj (2005) find that individuals contribute their knowledge when they believe that it will enhance their professional reputation, they have sharing experience and they are within the organization's network.

Image can be an important social factor that influences knowledge-sharing attitudes and the intention to use knowledge-sharing systems within an organization. Imaging is the degree to which an individual believes that using an innovation improves one's position in the social system (Moore \& Benbasat, 1991). Therefore, an individual may find that using a particular system is beneficial because it enhances his/her image. Image can be an important element for sharing knowledge through inter-organizational systems as it can improve individuals' social awareness and reputation not only in their organization but also in other firms with their whole area of expertise and thus encourage them to share knowledge. Bock et al. (2005) find that subjective standards, associated with images, influence individuals' intention to share knowledge. The subjective standard refers to perceived social pressure to perform or not to behave (Ajzen, 1991). In the inter-organizational context, Yang \& Maxwell (2011) pointed out that everyone is motivated to contribute to the collective interest in an organization, as long as they maintain their social reputation. Participating scientists share knowledge about different types of knowledge; in which knowledge related to research, teaching and learning is shared most often. There is ample evidence that there is a culture of knowledge sharing hidden in universities. For example, researchers have a positive attitude and intention toward knowledge sharing. Along with this they had a high expectation of some personal benefit or reward as a result of their knowledge sharing. Specifically, they expect knowledge sharing to improve and expand relationships with colleagues, and to provide opportunities for internal promotion and career development at other universities. They are also aware of such a cultural norm that they believe that both managers and colleagues will participate in knowledge sharing. These findings are completely consistent with other studies on knowledge sharing in universities. In the study of knowledge sharing at a specialized university in Malaysia, Cheng et al. (2009) found that researchers are encouraged to share if they are aware of incentives and reward mechanisms to encourage knowledge sharing, even without incentives to engage them. Cabrera et al. (2006) and Lin (2007) find that a person's confidence in sharing one's useful knowledge will lead to knowledge sharing. Similarly, Kankanhalli et al. (2005); Hsu et al. (2007), Chen \& Hung (2010) found that employees with high self-knowledge sharing tend to engage in knowledge-contributing behaviors rather than people with low beliefs and confidence. Regular sharing of common knowledge leads to a high ability to share important knowledge (Nonaka et al., 2006). Sharing a significant amount of relevant knowledge in an organization will enhance its cohesion and influence. It is found that the more useful knowledge shared by a specific individual within an organization, the individual becomes a clearer and more attractive source of knowledge (Cross \& Gray, 2013).

\subsection{Knowledge sharing recipients}

Szulanski (1996) argues that a person's ability to absorb knowledge must be associated with their ability to interpret 
and to value the information of others. Based on social capital theory, knowledge sharing often (while not always) leads to reciprocity (Nahapiet \& Ghoshal, 1998; Schultz, 2001). In general, the standard of reciprocity is one of the main components of ethical rules in the social system (Černe et al., 2014), meaning that workers share a significant amount of knowledge. Work-related jobs are also more likely to receive relevant knowledge in the same process. However, knowledge sharing is not always reciprocal and there may be a level of asymmetry (Cabrera and Cabrera, 2002). At the same time, knowledge itself is an organization and collective phenomenon (Spender, 1996), and knowledge sharing will connect sharers and receivers into an interactive context with the value of knowledge placed under collective supervision. Tsoukas (1996) states that knowledge-sharing individuals are more likely to be connected to related knowledge created by other firms, and can use that knowledge to work better in daily work. The argument here is that connecting and accessing relevant internal organizational knowledge can greatly lead to improved job performance.

Besides, Assudani (2009), Riege (2005), Kyobe (2010) said that the ability to acquire and absorb knowledge is a barrier to sharing knowledge. The ability to acquire and absorb knowledge is defined as the ability of an organization to determine the value of new knowledge and use it (Cohen \& Levinthal, 1990). Thus, for the recipient to share the knowledge to achieve the desired effect, it is necessary to improve the ability to receive and absorb their knowledge.

\subsection{Advantages and disadvantages in knowledge sharing activities}

Tacit knowledge owned by individuals is a very important factor for the operation and survival of the organization. However, how to make employees willing to share knowledge is the most difficult bottleneck. Knowledge sharing is one of managers' biggest challenges, because employees often do not want to participate in this knowledge sharing. Contribution is not only time-consuming but it can also be a threat to their position in the organization (Bukowitz \& Willams, 1999). Knowledge sharing is directly related to an organization's advantage competitive, because undisclosed knowledge will slow down the improvement of an organization. But unless the organizational environment has a policy of rewarding and encouraging effective sharing of knowledge, attempts to institutionalize the knowledge management system will fail (Serban \& Luan, 2002). Researchers seem to agree that knowledge sharing issues often stem from social dilemmas, knowledge dilemmas, and a combination of both (Cabrera \& Cabrera, 2002; Osterloh \& Frey, 2000), which causes an act of knowledge that is counterproductive to the common good of the organization. There is no common identity (Brown \& Duguid, 2000; Davenport et al., 1998) and there is no relationship between the recipient and the knowledge sharing person (Davenport \& Prusak, 1998; Hansen, 1999).

A number of studies have shown that organizational culture is a barrier to promoting knowledge sharing effectively within an organization (David \& Fahey, 2000; McDermott \& O'dell, 2001). The cultural differences have been identified as the biggest obstacle to effective knowledge sharing (Alavi \& Leidner, 2001; Li, 2010). Culture specific to some countries, such as China, can be a barrier to knowledge sharing. Chow \& Chan (2008) suggested that future research should include social capital factors such as organizational culture and social networks to learn how to cultivate knowledge sharing. Moreover, Riege (2005) argues that very few studies have identified barriers to knowledge sharing in large firms. Especially in public universities in East Asia, organizational culture is not based on trust, socialization, effective communication, rewards and recognition compared with the culture in Western countries. Most of the previous research has focused on the private sector or developed countries with high-tech firms, supportive cultures and good knowledge-sharing activities (Bate \& Robert, 2002; Bontis et al., 2009; Hall \& Mairesse, 2006; Kim \& Lee, 2006; Michael, 2007). These researchers think it is important to promote knowledge sharing in developing countries to investigate the reasons behind knowledge accumulation among employees, especially among scientists in the public sector in these countries (Muhenda \& Lwanga, 2014).

Researches have shown that knowledge is an energy source, and employees collect knowledge for personal gain. Employees accumulate knowledge to increase their influence and maintain the expression worthy of their superiors. Moreover, culture in public universities without effective communication, socialization, social trust and ineffective networks will hinder the practice of knowledge sharing. In addition, a non-supporting culture, the affect from the need for power, the opportunity for promotion, the need to impress the superior and the link between reward and knowledge sharing can influence adversely knowledge sharing behavior in public universities (Farwa Muqadas et al., 2017). Social theory provides the reason why knowledge sharing may not occur. Because of the natural instinct of protecting oneself, individuals are primarily self-serving (Leana \& Van Buren, 1999), especially when a potential cost loss is perceived. The dilemma manifests as sharing or not sharing knowledge (Barachini, 2009; Kollock, 1998; Wasko \& Faraj, 2000). There is a choice between spending time and effort to share knowledge and vice versa (Barachini, 2009).

Organizational structures are also considered to have a significant impact on knowledge sharing (Walczak, 2005). The structure of the organization is always different from universities and commercial firms. Tippins (2003) points out that the organizational structure and functions of higher education institutions can be a significant barrier to knowledge sharing, such as physical and psychological barriers. The relationship between employees of an 
organization, especially among members of different groups, becomes another barrier to knowledge transfer (O'Dell \& Grayson, 1998; Riege, 2005; Assudani, 2009). Ignorance is caused by those who are intellectually unable to see, and those who need knowledge do not know who has it (O'Dell \& Grayson, 1998), which is seen as a relationship barrier.

Time has been identified as a barrier to knowledge sharing (McDermontt \& O'Dell, 2001; Riege, 2005; Yao et al., 2007). Workers are often overwhelmed at work, find it difficult to find time to share knowledge with their colleagues (Yao et al., 2007). Even in the best firms, it takes on average 27 months to disseminate best practices. This means that the delay lasts more than two years, which is a problem in an economy that is constantly evolving and changing (O'Dell \& Grayson, 1998).

Geographic distance is considered as a barrier for knowledge sharing (Levina \& Vaast, 2005; Kotlarsky et al., 2008; Martins et al., 2004; Assudani, 2009) because it reduces or completely eliminates except for face-to-face interaction and making the nature of knowledge sharing more difficult.

\section{Some issues raised for Vietnamese universities}

Universities have long been considered an important institution of the society. They carry out the responsibility of conducting scientific research, teaching and publishing publications in academic environments. University lecturers focus their attention on research activities to gain professional knowledge and ensure the role of the "master machine" of a lecturer. Universities provide facilities with research and development opportunities to meet emerging educational technologies (Zeichner, 2003). In addition, universities have an intensive knowledge environment and play a central role in creating knowledge through research, dissemination of knowledge through publications. Lecturer also plays an important role in knowledge transfer through collaboration with businesses/firms to support socio-economic innovation, and in learning support through their training curriculum and research. Many knowledge sharing research have been carried out in universities, with different contexts, working environments and all looking to find the answer to the question of how knowledge can be managed and share most effectively? Many researchers recognized the importance of environment and organizational culture in designing knowledge management strategies and in finding tools to promote and facilitate knowledge sharing (Hislop, 2009; McDermott \& O'Dell, 2001). However, few empirical studies have been carried out, especially in exploring the factors that can affect knowledge sharing in universities.

In addition, the role of a leader can be quite different in an university in comparison to other organization types. Yielder \& Codling (2004) suggest that there are two types of leadership in higher education. The academic leadership attribute highlights knowledge, expertise and expertise, personal qualities and group acceptance. Therefore, the power base is focused on one individual. In contrast, management leadership emphasizes decentralization and job responsibilities. Control of powers and powers is delegated to the job, not to an individual. Accordingly, academic leadership is more widely practiced in more traditional universities, while management leadership is more closely associated with the type of firm (business) model that many universities are aiming for.

In addition, there is extensive discussion of the role of organizational culture in promoting knowledge sharing (Hislop, 2009), although there is some debate about whether cultural change should be a part of the knowledge management program (McDermott \& O'Dell, 2001). Should knowledge management initiatives try to fit into existing culture? Liebowitz (2008) and Lee (2007) argue that academics are simple and complex people, suggesting that cultures may differ between faculties in different disciplines. Taylor (2006) discusses another division within UK universities: between universities founded before 1992 and universities established after 1992. Universities before 1992 are decribed to have a high degree of autonomy and are traditionally run by the academic community. Universities founded after 1992 have important departments, with a centralized and decentralized management structure, in which all employees report to online managers and have less autonomy.

Some researches suggest that, among universities, knowledge related to research, teaching and learning is shared most often. Scholars have a positive attitude and are intent on sharing knowledge. Along with knowledge sharing, they expect some personal or other benefits as a result of knowledge sharing. Specifically, they expect their participation in knowledge sharing to improve and expand relationships with peers; provide opportunities for internal promotion and career development in other universities. They are also aware of a cultural norm that both managers and colleagues are expected to participate in knowledge sharing. These findings are consistent with other studies on university knowledge sharing. Cheng et al. (2009) found that scholars are motivating teachers to share knowledge if they perceive incentives and reward mechanisms to encourage knowledge sharing, even if there is no immediate reward. ie they do not share knowledge. Universities need to find ways to participate in initiatives that can improve the way that knowledge is created, shared and disseminated. Further research will support the development of a smart and appropriate approach to leveraging existing knowledge-sharing cultures at universities. Some implications for Vietnam:

(i) Future researchers may be conducted to explore the role of scholars and students in enhancing knowledge sharing in educational institutions. Cross region and transnational studies can also provide useful solutions that can highlight the culture, values and structure of an organization and to identify patterns of knowledge sharing 
between undergraduate and graduate students, between lecturers of different university types. In addition, conditions related to the benefits of knowledge sharing can be assessed and considered because too much knowledge sharing can lead to redundancy and additional costs (Foss et al., 2010). Future studies may also include multi-level models, in which the "trend - behavior - performance" linkage will be integrated into the framework of larger organizational activities. Such a task is difficult to perform empirically, but it can lead to insights.

(ii) A suggestion for further research is to conduct quantitative research on the relationship between barriers and knowledge sharing. In order to understand the impact of barriers on knowledge-sharing behavior, researchers should apply the knowledge-sharing costs of recognition including the barriers and potential factors for examples political and organizational barriers, management commitment, lack of trust (Riege, 2005); time, cost, distance, region, culture, technology.

(iii) Future researchers may also investigate if repeated knowledge sharing can facilitate the development of trust between the parties even in the absence of face-to-face contact as is the case with virtual groups. Furthermore, research will be needed if repeated knowledge sharing affects the development of trust between knowledge sharing parties.

\section{References}

Andrews, K.M. and Delahaye, B.L. (2000), "Influences on knowledge processes in organizational learning: the psychosocial filter”, Journal of Management Studies, 37(6), 797-810.

Anantatmula, V.S. (2007), "Linking KM effectiveness attributes to organizational performance”, VINE, 37(2), 133-149.

A. K. Sinha, D. Arctur, I. Jackson, and L. Gundersen. (2011), In book: Societal Challenges and Geoinformatics, Chapter: Infusing Semantics into the Knowledge Discovery Process for the New e-Geoscience Paradigm, Publisher: Geological Society of America Special Paper 482, 165-181.

Alavi, M., Leidner, D. (2001), Knowledge Management Systems: Issues, Challenges and Benefits, Communications of the Association for Information Systems (AIS).

Al Saifi, S.A., Dillon, S. and McQueen, R. (2016), The relationship between face to face social networks and knowledge sharing: an exploratory study of manufacturing firms, Journal of knowledge management, 20(2), 308-326.

Andolsek, D.M. (2011), Knowledge hoarding or sharing, paper presented at the Knowledge as Business Opportunity: Proceedings of the Management, Knowledge and Learning International Conference 2011, 167176.

Bautista, R.G. and Bayang, M.A. (2015), Social network, social trust and shared-goals towards organizationalknowledge sharing, American Journal of Educational Research, 3(5), 662-667.

Bate, S.P. \& Robert, G. (2002), "Knowledge management and communities of practice in the private sector: lessons for modernizing the National Health Service in England and Wales”, Public Administration, 80(4), 643-663.

Bock, G., Lee, J., Zmud, R.W. (2005), Behavioural intention formation in knowledge sharing: examining the roles of extrinsic motivators, socio-psychological forces and organizational climate, MIS Quarterly.

Bontis, N., Bart, C., Sáenz, J., Aramburu, N. and Rivera, O. (2009), "Knowledge sharing and innovation performance: a comparison between high-tech and low-tech companies”, Journal of Intellectual Capital, $10(1), 22-36$.

Chaudhry, A. (2005), Knowledge sharing practices in Asian institutions: a multi-cultural perspective from Singapore, 71th IFLA General Conference and Council on World Library and Information Congress.

Chow, W.S. and Chan, L.S. (2008), Social network, social trust and shared goals in organizational knowledge sharing, Information \& Management, 45(7), 458-465.

David Gurteen (1999), Creating a Knowledge Sharing Culture, Knowledge Management Magazine, 2(5).

David, W. and Fahey, L. (2000), Diagnosing cultural barriers to knowledge management, The Academy of Management Executive, 14(4), 113-127.

Davenport, H. T., Prusak, L. (1998). Working Knowledge: How Organizations Manage What They Know. Boston: Harvard Business School Press.

Davenport, H. T., De Long, D. W., Beers, M. C. (1998). Successful Knowledge Management Projects, Sloan Management Review.

De Long, D. W., Fahey, L. (2000). Diagnosing Cultural Barriers to Knowledge Management, Academy of Management Science.

Grant, R.M. (1996), Toward a knowledge-based theory of the firm, Strategic Management Journal, 17, 109-122.

Haas, M.R. and Hansen, M.T. (2007), Different knowledge, different benefits: toward a productivity perspective on knowledge sharing in organizations, Strategic Management Journal, 28(11), 1133-1153.

Hall, B.H. \& Mairesse, J. (2006), “Empirical studies of innovation in the knowledge-driven economy”, Economics of Innovation and New Technology, 15(4/5), 289-299. 
Hansen, M.T. (2002), Knowledge networks: explaining effective knowledge sharing in multiunit companies, Organization Science, 13(3). 232-248.

Henri, (2016), "Review of empirical research on knowledge management practices and firm performance”, Journal of knowledge management, 20(2), 230-257.

Hislop, D. (2009), Knowledge Management in Organizations, 2nd ed., Oxford University Press, Oxford.

Holten, A.-L. et al. (2015), "Knowledge hoarding: antecedent or consequent of negative acts? The mediating role of trust and justice”, Journal of Knowledge Management, 20(2), 215-229.

Imran. et al. (2016), "Organizational learning through transformational leadership”, The Learning Organization, 23(4), 232-248.

Stiglitz, J.E. \& Greenwald, B. (2003), “Towards a New Paradigm in Monetary Economics”, Cambridge University Press.

Kim, S. and Lee, H. (2006), The impact of organizational context and information technology on employee knowledge-sharing capabilities, Public Administration Review, 66(3), 370-385.

Lee, S., Gon Kim, B. and Kim, H. (2012), An integrated view of knowledge management for performance, Journal of Knowledge Management, 16(2), 183-203.

Lee, C.K., Hawamdeh, S. (2002), Factors impacting knowledge sharing, Journal of Information and Knowledge Management.

Lee, J. (2007), The shaping of departmental culture: measuring the relative influence of the institution and discipline, Journal of Higher Education Policy and Management.

McDermott, R. and O'dell, C. (2001), Overcoming cultural barriers to sharing knowledge, Journal of Knowledge Management, 5(1), 76-85.

Michael, K. (2007), "Knowledge sharing and organizational change in a leading telecommunications equipment vendor: a case study on Southern Networks", Journal of Cases on Information Technology (JCIT), 9(3), 5070.

Muhenda, M.B. and Lwanga, E.K. (2014), "Knowledge hoarding among academic staff in higher education institutions in Uganda: risk or strategy”, World Review of Business Research, 4 (2), 279-290.

Muqadas, F., Ilyas, M. and Aslam, U. (2016), Antecedents of knowledge sharing and its impact on employees' creativity and work performance, Pakistan Business Review, 18(3), 655-674.

Nelson, R.R. \& Winter, S.G. (1982), "The Schumpeterian tradeoff revisited”, The American Economic Review, 72(1), 114-132.

Nonaka, I. (1994), The dynamics theory of organisational knowledge creation, Organisation Science.

Nonaka, I. and Takeuchi, H. (1995), The Knowledge-Creating Company: How Japanese Companies Create the Dynamics of Innovation. London: Oxford University Press.

Park, S. and Kim, E.-J. (2015), Revisiting knowledge sharing from the organizational change perspective, European Journal of Training and Development, 39(9), 769-797.

Murray, P. (2002), Knowledge management as a sustained competitive advantage, Ivey Business Journal.

Postolache, A. (2017), 5 Benefits of Knowledge Sharing within an Organization, https:// www.quandora.com/5benefits-knowledge-sharing-organization/, accessed June 15, 2019.

Refaiy, M. and Labib, A. (2009), "The effect of applying tacit knowledge on maintenance performance: an empirical study of the energy sector in the UK and Arab countries", Knowledge Management Research \& Practice, 7, 77-288.

Riege, A. (2005), Three-dozen knowledge-sharing barriers managers must consider, Journal of Knowledge Management, 9(3), 18-35.

Rutten, W., Blaas-Franken, J. and Martin, H. (2016), The impact of (low) trust on knowledge sharing, Journal of Knowledge Management, 20(2), 199-214.

Smith, K.G et al. (2006), "Knowledge exchange and combination: the role of human resource practices in the performance of high-technology firms", Academy of Management journal, 49(3), 544-560.

Svetlik, I., Stavrou-Costea, E. and Lin, H.-F. (2007), Knowledge sharing and firm innovation capability: an empirical study, International Journal of Manpower, 28(3/4), 315-332.

Yang, J.-T. (2007), Knowledge sharing: investigating appropriate leadership roles and collaborative culture, Tourism Management, 28(2), 530-543.

Yi, W., Qing, X., Lijun, M.. (2008) Influential Factors to Knowledge Sharing between Intra-Organizational Members. A Literature Review. Journal of Xidian University, 4, 46-52.

Yielder, J. and Codling, A. (2004), "Management and leadership at a contemporary university”, Journal of Higher Education Policy and Management, 26(3), 315-28.

Zeichner, K.M. (2003), "Teacher research as professional development for P-12 educators in the USA", Educational Action Research, 11(2), 301-326. 